\title{
O cuidado de si e a preparação para improvisação musical livre
}

Care of the self and the preparation for free musical improvisation

Pedro Azevedo Sollero ${ }^{1}$ pedrosollero@gmail.com 


\section{Resumo}

O presente artigo procura contribuir para reflexões sobre diferentes processos de preparação para a improvisação musical livre, a partir da ideia de "cuidado de si", como apresentada por Michel Foucault em sua Hermenêutica do Sujeito. O filósofo realiza um estudo deste conceito e práticas associadas, entre filósofos clássicos, e o acompanha até o momento histórico de Descartes, quando é dissociado do "conhece-te a ti mesmo". Por meio da revisão da obra de Foucault, buscarei descrever conceitos que possam nos ajudar a olhar para práticas de preparação para a improvisação musical livre. Como referência de estudos em aprendizado de improvisação musical, apresentarei ideias de pesquisas que aproximam a música das ciências cognitivas. Por fim, farei uma reflexão a partir das práticas e conhecimentos descritos na bibliografia, e buscarei ferramentas para a compreensão da preparação para a improvisação musical livre, que contemplem mais do que o ensaio motor das ações da performance.

Palavras-chave: improvisação musical livre; Foucault; ciências cognitivas.

\section{Abstract}

The present article aims to contribute to reflections regarding different processes of preparation for free musical improvisation, with aid of the idea of "care of the self", as presented by Michel Foucault in the Hermeneutics of the Subject. The philosopher conducts a study of this concept and associated practices, among classic Greek philosophers and follows it to the time of Descartes when it is dissociated from "know thyself". By way of revision of Foucault's work, we shall attempt to describe concepts which may aid us in looking at practices of preparation for free musical improvisation. As reference for studies in the field of learning musical improvisation, we shall present ideas from researches which bring together music and cognitive sciences. Lastly we shall offer our reflection based on the practices studied herein, and we shall search for tools for the comprehension of the preparation for free musical improvisation, which contemplate more than the motor rehearsal of the actions of the performance.

Keywords: free musical improvisation, preparation, care of the self. 


\section{Introdução}

Este trabalho pretende refletir sobre alguns aspectos da preparação individual para a improvisação musical livre solo e em grupo sob a luz de trabalhos distintos que estudam preparações para atividades improvisadas. Nossa referência principal será o trabalho de Michel Foucault em sua Hermenêutica do Sujeito. Este estudo sobre o conceito de cuidado de si na filosofia clássica, descreve processos e práticas de preparação para diversas atividades que dependem da interação eficiente do sujeito com o momento presente. A saber, a retórica, a medicina, as lutas, a música, o trabalho agrícola, etc. Além do conhecimento teórico que antecede o momento do exercício, uma série de práticas acompanha os dias daqueles que buscam a virtude para que se possa internalizar conteúdos e capacidades que tornam este exercício possível. Como ferramenta para entender certos aspectos desta internalização estabelecerei um diálogo com autores que escreveram especificamente sobre o aprendizado da improvisação, no âmbito das ciências cognitivas.

Na primeira parte do trabalho, por conta da obra de Foucault não ser diretamente uma reflexão sobre música, descreverei os motivos pelos quais acredito que a pesquisa e as reflexões deste filósofo podem contribuir para a investigação sobre práticas individuais de músicos improvisadores. Para tanto farei uso de termos e conceitos da filosofia grega e romana, estudada por Foucault, que serão aprofundados na primeira parte do artigo.

Em seguida, falarei sobre aspectos da preparação para a improvisação sob o ponto de vista das ciências cognitivas tendo como principais referências os trabalhos de Jeff Pressing, Rogério Costa, Stéphan Schaub e Aaron Berkowitz. Berkowitz utiliza, entre outros autores da psicologia cognitiva e neurociências, a obra de Pressing e suas ferramentas teóricas para compreender diferentes processos improvisatórios musicais. Estas referências, nos oferecem estudos detalhados de processos mentais subjacentes e explícitos, relacionados à criação de música em tempo real. A escolha de um material como a obra de Berkowitz, que descreve processos de desenvolvimento de fluência dentro de territórios idiomáticos, dá-se como uma busca por contemplar parte da formação de muitos musicistas que após anos de experiência dentro de territórios específicos, aventuram-se pela improvisação livre. Acredito que esta referência mostra sua relevância uma vez que práticas pedagógicas e estratégias de aprendizado talhados para outras maneiras de se fazer música ocupam frequentemente parte notável no discurso de musicistas de improvisação livre a respeito do que compreendem como determinante em seus processos de preparação para improvisar. Costa e Schaub colocam, em artigo de 2013, que todo o passado musical que cada um carrega para dentro da sala de ensaio, ajuda a formar o plano de consistência da improvisação livre. Os autores expandem, neste mesmo artigo, os conceitos de Pressing em uma reflexão sobre a improvisação musical coletiva livre. Esta importante contribuição para a presente reflexão será também tratada na segunda parte do presente trabalho.

Por fim, apresento a conclusão na qual busquei refletir sobre como as ideias de Michel Foucault e as referências relacionadas às ciências cognitivas podem nos auxiliar 
em uma reflexão sobre diferentes práticas adotadas na preparação para a improvisação musical livre. As referências aqui levantadas não devem servir como moldura para encaixar qualquer processo criativo musical. Talvez possam, porém, ajudar a quem possa se interessar por compreender estes processos de maneira um pouco mais ampla. As ideias que apresentarei neste artigo intentam somente levar o olhar para questões determinantes para diferentes improvisadores à luz de autores que tratam da preparação para improvisar sob ângulos distintos.

\section{Parte 1: Michel Foucault e o cuidado de si}

A questão tratada por Michel Foucault na Hermenêutica do Sujeito é das mais antigas e difíceis e certamente extrapola a improvisação musical ou de qualquer tipo: como, através do cuidado de si, se dá a construção do próprio sujeito. O termo grego, Epiméleia heautoû, traz as ideias de "cuidado de si mesmo, ocupar-se de si mesmo, preocupar-se consigo" (FOUCAULT, 2014).

A escolha por Foucault vem de uma busca por reflexões a respeito da preparação para agir sem roteiro definido. Atividades que dependem do momento presente e suas imprevisibilidades. Entende-se aqui por preparação, mais do que o ensaio técnico motor do que será apresentado ao público.

Conquanto a preparação para a música composta em tempo diferido exija igual assiduidade, nesta há uma distinção fundamental: alvos claros. A improvisação é sempre um salto no escuro. Como então preparar-se para o desconhecido? Esta pergunta é antiga e para os filósofos estudados por Foucault aplica-se a diversas atividades como o trabalho agrícola, a oratória e a música. Todas estas dependem em grande parte do momento e contexto em que acontecem e podem supor uma preparação rica e variada que os contemple.

Em uma compreensão ampla de diferentes processos de preparação, a obra do filósofo francês nos traz a ideia de cuidado de si e a observa em escolas filosóficas específicas como forma de organizar práticas e técnicas na busca da virtude e da construção do sujeito. Foucault define cuidado de si como "uma atitude geral para consigo, para com os outros, para com o mundo". Para Sócrates, "o cuidado de si é... um princípio de movimento, um princípio de permanente inquietude da existência... o momento primeiro do despertar" (FOUCAULT, 2014). Esta construção se dá por meio de sistemas de práticas e conhecimentos que se organizam sob este conceito. Que técnicas e estratégias nos ajudam na insistência necessária para se atingir a virtude que somente pode ser atingida com reiterado e inabalável esforço?

Embora este tipo de reflexão não seja corrente no estudo acadêmico da música, outras áreas o tem em grande importância. Na filosofia, além de Foucault, o filósofo alemão contemporâneo Peter Sloterdijk traz o conceito de "antropotécnica"1 ; no teatro, 
Stanislavski fala do "trabalho do ator sobre si mesmo"2 ; Artaud, do "atletismo afetivo"3 ; Grotowski, "a arte como veículo"4 . Todos, de alguma forma, descrevem conjuntos de práticas e estratégias que extrapolam o domínio técnico específico da atividade em desenvolvimento e são determinantes no processo. Referências à formas de cuidados de si também podem ser encontradas muito antes na história e certamente ultrapassam o momento observado por Foucault. Desta forma o autor justifica sua escolha por uma questão, em suas próprias palavras, de "legibilidade do fenômeno":

(...) chega-se nos séculos I-II a uma cultura de si, a uma prática de si cujas dimensões são consideráveis, cujas formas são muito ricas e cuja amplitude, que certamente não representa nenhuma ruptura de continuidade, permite uma análise sem dúvida mais detalhada do que se nos reportássemos a uma época anterior.

(FOUCAULT, 2014, p.282)

As formas estoicas de cuidado de si estudadas pelo filósofo francês compreendem a preparação de maneira ampla. Grosso modo, envolvia o conhecimento teórico de mundo (Mathésis) e as práticas (Áskesis) através das quais se buscava a virtude. É interesse desta pesquisa, neste momento, o segundo dos dois termos: Áskesis, que envolve da simulação prática do ato a se realizar (Gymnázein) às diferentes formas de meditação a seu respeito (Melatân). Falarei sobre estas duas etapas da Áskesis mais adiante, por ora, talvez possamos especular que a riqueza dos conceitos e práticas descritos pelos filósofos gregos estudados por Foucault, pode nos ajudar a compreender a preparação para a improvisação musical livre para além da repetição de movimentos que, ao atingirem um ideal, serão apresentados ao público ou gravados.

A ascese estoica intenta que o sujeito esteja pronto para o que the possa acontecer e o equipa para que possa obter êxito. Este equipamento, fruto da Áskesis, é o que os gregos chamam paraskeué. Esta é "a estrutura de transformação permanente dos discursos verdadeiros... elemento de transformação do logos em êthos." (FOUCAULT, 2014, p. 291). É através da paraskeué que o discurso que se pretende internalizar se torna parte do sujeito. As frases que compõe este discurso, muitas vezes ditas em voz alta ou escritas, ganham materialidade e tornam-se a prática deste sujeito que se constrói. Visto por um olhar musical, além da compreensão mais imediata que nos remete à aquisição de conteúdos musicais específicos, talvez haja ressonância na maneira com que determinados preceitos de escuta e interação tornam-se parte ativa e imanente de cada improvisador por meio de esforços que envolvem práticas individuais e coletivas.

A respeito de práticas individuais, Foucault nos apresenta o trabalho de Musonius Rufus, filósofo estoico, que discorre sobre a ascese filosófica e fala em exercícios de corpo, de alma, e de corpo e alma. Musonius concentra-se nos dois últimos. Embora não ofereça detalhes específicos a respeito destes exercícios, Foucault aponta que para Rufus, estes tinham função de reforçar a coragem (Andreia) e o domínio de si (Sophro-

\footnotetext{
2 In: STANISLAVSKI, 1989

$3 \quad$ In: ARTAUD, 2006

4 In: FLASZEN, 2010
} 
zyne). Ambas características determinantes em qualquer improvisação. A tarefa, no entanto, está longe de ser simples.

Assimilar os discursos que se considera verdadeiros até que sejam parte inseparável de quem os estuda é um processo longo o suficiente para que a determinação e o foco sejam muitas vezes postos à prova. Segundo Rufus, a virtude só será alcançada "por um regime de resistência em relação à fome, ao frio, ao calor, ao sono... um corpo de paciência, um corpo de resistência, um corpo de abstinências." (FOUCAULT, 2014, p. 384) Ainda que estes regimes fossem aplicados de tempos em tempos, e não de maneira contínua, exigiam um esforço considerável. Por conta da enorme dificuldade desta busca, faz-se necessário algo que proteja o sujeito em seu caminhar.

O primeiro suporte da ascese estoica, a paraskeué, garante que independente das circunstâncias, será mantido o rumo à meta primordial. Traduzida por Sêneca por instructio, a paraskeué é constituída pelos discursos dos quais se pretende apropriar. Sendo assim, representa "o que se poderia chamar de uma preparação ao mesmo tempo aberta e finalizada do indivíduo para os acontecimentos da vida." (FOUCAULT, 2014, p. 286) Para este fim, são adotados exercícios ascéticos que, embora envolvam renúncias e elementos de austeridade, diferem da ascese cristã no sentido de que não têm como objetivo inicial a renúncia de si, e sim, a constituição de si memo. Diferente da ascese cristã do final do século XVI e início do XVII que previa exercícios específicos a serem praticados em horas certas, a Áskesis parece sugerir um caminho mais conducente a um corpo e mente criativas e livres que se adaptam mais facilmente à novas realidades. O rigor da predeterminação extrema é preterido, como mostra Foucault na citação abaixo, em nome de um sistema que depende da constante reavaliação de si e de todas as potencialidades do sujeito para que se determine a forma mais adequada de ação a cada momento. A respeito dos exercícios da ascese filosófica Foucault aponta que:

\footnotetext{
Temos algumas indicações de regularidade. Algumas formas de exame da manhã são recomendadas, exame que se deve fazer pela manhã e que diz respeito às tarefas que devem ser cumpridas durante o dia. Recomenda-se o exercício da noite (exame de consciência), esse, bem conhecido. Mas afora estes poucos pontos de referência, trata-se muito mais de uma livre escolha destes exercícios pelo sujeito, no momento em que os julgar necessários. São apenas fornecidas algumas regras de prudência, ou algumas opiniões sobre a maneira de realizar estes exercícios (...) (FOUCAULT, 2014, p.380).
}

Para os filósofos estudados nesta obra de Michel Foucault a questão da técnica é colocada em campo mais amplo e insere-se dentro de uma preparação que embora seja feita por alguém que exerce uma atividade específica na qual intenta desenvolver-se, também deve contemplar uma dimensão ética que visa desenvolver o sujeito como um todo. Esta maneira de enxergar a preparação musical talvez não seja tão comum quanto o paradigma cuja origem Foucault associa ao que chama de "momento cartesiano". É neste momento que o filósofo observa um processo determinante para a estruturação da maneira como entendemos algumas relações éticas entre o que fazemos e o que somos. Não à toa, esta questão recebe considerável atenção na primeira aula de Foucault no Collège de France, curso que compõe os textos da Hermenêutica do Sujeito. É neste 
"momento cartesiano" que instaura-se, segundo o filósofo, o Conheça-te a ti mesmo (gnôthi seautón) como princípio fundador do procedimento filosófico:

Com efeito, e nisso as coisas são muito simples, o procedimento cartesiano, que muito explicitamente se lê nas Meditações, instaurou a evidência na origem, no ponto de partida do procedimento filosófico - a evidência tal como aparece, isto é, tal como se dá, tal como efetivamente se dá à consciência, sem nenhuma dúvida possível... É portanto, ao conhecimento de si, ao menos como forma de consciência, que se refere o procedimento cartesiano (FOUCAULT, 2014, p. 15).

No entanto, esta expressão tão presente em torno do personagem de Sócrates é, neste momento, requalificada filosoficamente em relação ao seu uso e significado original. Foucault nos aponta para o texto Socrático intitulado Alcibíades 5 mostra como a "epiméleia heautoû" (o cuidado de si) é realmente o quadro, o solo, o fundamento, a partir do qual se justifica o imperativo do "conhece-te a ti mesmo". (FOUCAULT, 2014) Vemos em Epicteto e outros estoicos tardios que Sócrates é aquele que aborda os jovens na rua e os incita a ocuparem-se consigo mesmos. Dizia o filósofo: "ocupai-vos com tantas coisas, com vossa fortuna, com vossa reputação, não vos ocupais com vós mesmos." Esta base para o conheça-te a ti mesmo que previa o envolvimento total do sujeito na busca da virtude é a epiméleia heautoû. Foucault observa que:

O cuidado de si é uma espécie de aguilhão que deve ser implantado na carne dos homens, cravado na sua existência, e constitui um princípio de agitação, um princípio de movimento, um princípio de permanente inquietude no curso da existência (FOUCAULT, 2014, p. 9).

O cuidado de si, descrito por Foucault como "uma atitude geral para consigo, para com os outros e para com o mundo" (FOUCAULT, 2014) é impulsor e organizador de conjuntos de práticas que visam construir o sujeito virtuoso deve, para os filósofos estudados, conduzir o sujeito não a uma regra de vida, mas a uma arte de viver (tékne toû bíou). Segundo Foucault:

Creio que isso não deve ser esquecido. Fazer da própria vida, objeto de uma tékne, portanto, fazer da própria vida uma obra - implica necessariamente a liberdade e a escolha daquele que utiliza sua tékne. Se a tékne devesse ser um corpus de regra às quais seria preciso submeter-se de ponta a ponta, minuto a minuto, instante a instante, se nela não houvesse precisamente essa liberdade do sujeito, fazendo atuar sua tékne em função de seu objetivo, do desejo, de sua vontade de fazer uma obra bela, não haveria aperfeiçoamento da vida (FOUCAULT, 2014, p.381).

Embora sejam ricas, nos textos estudados pelo filósofo francês, as referências à 
compreensão ampla dos processos de Áskesis, também fazem-se presentes questões mais diretamente ligadas ao desenvolvimento técnico da atividade que se almeja dominar. Entre os autores que discorrem sobre este aspecto da Áskesis encontramos Demetrius. Este filósofo, indica, na citação que segue, como dever ser o treinamento de um atleta:

(...) alguns movimentos elementares, mas suficientemente gerais e eficazes para que possam ser adaptados a todas as circunstâncias, e para que possamos - sob a condição de serem também suficientemente simples e bem adquiridos - deles dispor sempre que necessário (FOUCAULT, 2014, p. 286).

Entretanto, não é fácil manter-se em constante estado de busca. O processo ascético deve, pois, possuir um suporte, como mencionei ao falar da paraskeué, que o mantenha em curso. É importante ressaltar que este suporte deve ter um caráter de socorro (Boethós) para que esteja sempre à mão. Para que se possa, em face do medo, preguiça, da contingência ou inconstância, prosseguir calmamente em seu caminho. Por meio de exercícios que devem criar esta ferramenta tão conveniente, os discursos ou lógoi assimilados, permitirão que se prossiga inabalado. A paraskeué, explica Foucault, deve deixar o sujeito mais forte do que o que possa lhe acontecer. Os exercícios que a compõe, como pretendo mostrar no parágrafo a seguir, são tanto de ordem motora quanto mental.

Embora haja alguma confusão em relação aos termos Gymnázein e Melatân (Plutarco e outros autores os utilizam como sinônimos), na maioria dos textos estudados por Foucault a distinção é bastante clara. Melatân é, em geral, um trabalho que o pensamento exerce sobre si mesmo com a função de preparar o indivíduo para o que deverá realizar. É descrita como um exercício de apropriação de um pensamento. O próprio termo epiméleia heautoû possui, segundo Foucault, uma relação etimológica com a palavra Melatân, colocando-a em posição fundamental em relação ao cuidado de si. Gymnázein, por sua vez, é estar efetivamente na presença de uma situação real, artificialmente provocada ou não, na qual se põe à prova aquilo que se faz. As compreensões do termo envolvem as ideias de exercitar-se, treinar, prova em realidade, o "trabalho sobre si em situação real" (FOUCAULT, 2014,p.382). Dois pontos introduzidos por Foucault se sobrepõe na Áskesis e nas formas de exercício que a compõe. São estes: os regimes de abstinência, dos quais falaremos primeiro, e a prática das provas.

Os regimes de abstinência são encontrados sob diferentes formas nos filósofos estudados por Foucault. Todavia, parece haver semelhanças entre os objetivos apontados por alguns destes pensadores. Musonius Rufus indica que os exercícios da ascese devem fortalecer a andreia (coragem) e sophrosyne (capacidade de moderar a si mesmo). Platão, ao discorrer, nas Leis, sobre a formação do bom cidadão (ou guardião), explica que nele deve-se formar ao mesmo tempo a coragem física e o domínio de si. Porém, se os objetivos são os mesmos, a natureza dos exercícios é inteiramente diferente. Ao passo que Platão vê na ginástica - literalmente nos exercícios físicos - a possibilidade de assegurar o desenvolvimento das virtudes, coragem e domínio, Rufus prescreve um regime de abstinências que deve aumentar a resistência à fome, ao frio, ao sono e ao des- 
conforto. O corpo que Musonius intenta moldar não é o corpo atlético, mas "um corpo de paciência, um corpo de resistência, um corpo de abstinências." (FOUCAULT, 2014, p.384) É também este o corpo que almeja Sêneca e outros filósofos da época. Um corpo de abstinências voluntárias que devem ser aplicadas não como regra de vida mas como um tratamento mais bruto ao qual o corpo é submetido de tempos em tempos para que se tenha sempre a clareza de que ainda que naquele momento se coma ou beba mais do que o necessário, a alimentação deve servir apenas para aplacar sua fome e a bebida apenas para mitigar sua sede. Este regime difere fundamentalmente das provas no sentido que são algo a que o sujeito se submete periodicamente enquanto a prova "deve tornar-se uma atitude geral em face do real" (FOUCAULT, 2014, p.387). Outra diferença importante está no fato de que a prova, ao contrário do regime de abstinências, comporta sempre um caráter de descoberta de si. Até onde se pode ir. Foucault associa à prova um importante processo de autoconhecimento, como indica o trecho abaixo:

trata-se, através dessa espécie de jogo aberto da prova, de demarcar a si mesmo, de medir o ponto de progresso em que se está, e de saber no fundo o que se é...A prova deve sempre estar acompanhada de um certo trabalho do pensamento sobre ele mesmo. (Foucault, 2014, p. 387)

Cabe ainda falar sobre um conceito fundamental para a compreensão do trabalho de Foucault e para a relação com a improvisação. A forma dos dizeres verdadeiros que compõe a paraskeué: a parrhesía. A forma com que os discursos verdadeiros que se quis assimilar (lógoi), transformam-se em prática (êthos). Etimologicamente, parrhesía significa falar com franqueza, abertura de coração, liberdade de palavra. A palavra parrhesía, segundo Foucault, refere-se a uma atitude moral, ao ethos e está ligada à decisão, escolha, à atitude de quem fala. Por outro lado refere-se também à técnica necessária para se transmitir o discurso verdadeiro. Esta capacidade de falar com liberdade é traduzida para o latim como libertas. Foucault explica:

É a abertura que faz com que se diga, com que se diga o que se tem a dizer, com que se diga o que se tem vontade de dizer, com que se diga o que se pensa dever dizer porque é necessário, porque é útil, porque é verdadeiro. (FOUCAULT, 2014, p. 327)

Refletir sobre processos musicais improvisatórios sob a luz desta rica pesquisa de Michel Foucault pode ajudar no olhar para práticas e eventos subjetivos, aparentemente extramusicais, nestes processos. Esta abordagem pode ajudar o pesquisador a fazer perguntas para as quais não seja necessário/possível chegar à soluções. Seria talvez de pouca utilidade listar e definir os conceitos apresentados por Foucault sem observar a reverberação destes mesmos conceitos na maneira como compreendo os traços deixados sobre os processos criativos sobre os quais me debruço. Grupos de práticas que apresentam aparentes semelhanças com os processos descritos por Foucault podem ser encontrados sem dificuldade na literatura musical.

Charles Mingus narra, em sua autobiografia6 ${ }^{6}$, como fazia para estudar mentalmen- 
te quando estava internado em uma instituição psiquiátrica e não tinha acesso a instrumentos musicais. Robert Fripp tem suas ideias musicais estudadas em livro de Eric $\mathrm{Tamm}^{7}$. . Neste trabalho, Tamm escreve sobre a forte influência do pensamento de George Gurdjieff sobre o músico inglês. O autor também ressalta a importância da constituição de si através de pequenos hábitos de um sujeito em constante desenvolvimento. A improvisadora e compositora Pauline Oliveros oferece importante contribuição para estudos sobre práticas de subjetivação associadas à música em seu livro Deep Listening: A composer's Sound Practice ${ }^{8}$.

Terminarei esta seção, portanto, com a definição de Foucault encontrada na obra de referência deste trabalho. Esta compreensão talvez possa nos ajudar a entender os processos de diferentes músicos improvisadores no sentido que os conceitos descritos por Foucault podem dar conta de diversas práticas que, ainda que difiram de um artista para o outro, são observadas como parte de uma história de buscas e aprendizados. Para Foucault:

(...) poderíamos chamar de "espiritualidade" o conjunto de buscas, práticas e experiências tais como as purificações, as asceses, as renúncias, as conversões do olhar, as modificações de existência, etc., que constituem, não para o conhecimento, mas para o sujeito, para o ser mesmo do sujeito, o preço a pagar para ter acesso à verdade (FOUCAULT, 2014, p.15).

\section{Parte 2: As ciências cognitivas e o aprendizado da improvisação}

Os processos de cuidado de si descritos na Hermenêutica do Sujeito são amplos e oferecem aspectos diversos que podem certamente ser aprofundados por meio da revisão bibliográfica de cada filósofo estudado por Foucault. No entanto, parece haver também uma outra possibilidade que talvez seja capaz de dar fruto a uma reflexão sobre o nosso objeto principal: processos de preparação para a improvisação musical livre. Esta possibilidade consiste em especular sobre a maneira como diferentes aspectos da vida de improvisadores vivos, na maneira como são por eles descritos, interagem para formar o que consideram seus processos de preparação para improvisar, ou cuidados de si na improvisação musical. A referência histórica de uma visão que contempla práticas tão distintas nos permite olhar ao mesmo tempo para processos com focos bastantes diferentes. Enquanto uma improvisadora musical pode dar crucial importância para a preparação da mente e da escuta, outra pode atribuir a qualidade de suas improvisações ao domínio técnico do instrumento e suas nuances. Ainda que ambas dominem os seus instrumentos e ambas pratiquem a calma e a escuta em seus improvisos.

A partir do próximo parágrafo, falarei sobre um trabalho que talvez esteja um pouco mais voltado para o processo descrito pela segunda improvisadora do exemplo

\footnotetext{
7 In: TAMM, 1990

$8 \quad$ In: OLIVEROS, 2005
} 
acima. No entanto, fica evidente na lista de habilidades necessárias à improvisação oferecida pelo improvisador e cientista cognitivo Jeff Pressing ${ }^{9}$, que as habilidades mentais tidas como fundamentais para a primeira improvisadora não são de forma alguma menos relevantes. $O$ motivo da escolha pelo trabalho que descreverei a seguir se dá pelo interesse deste artigo em um tipo específico de musicista. Embora a improvisação livre seja um ambiente aberto para pessoas de diferentes ocupações, idades e habilidades, este ambiente também é amplamente frequentado por pessoas que tiveram anos de treinamentos musicais específicos para o desenvolvimento de habilidades fortemente associadas a determinados idiomas musicais. É frequentemente dentro destes universos idiomáticos que se desenvolve o interesse pela improvisação. Também não é raro que estes mesmos idiomas sigam como parte da vida musical do improvisador em paralelo à improvisação livre ou como elementos desterritorializados dentro dela. Por este motivo, acreditamos que é de grande relevância o cuidadoso trabalho apresentado de Berkowitz sobre a improvisação idiomática, no sentido que, como vimos acima, os idiomas representam parte fundamental da construção dos referentes e bases de conhecimento de cada improvisador.

Os estudos, como o de Aaron Berkowitz acerca das maneiras com que estas habilidades podem ser desenvolvidas para improvisações idiomáticas, talvez interessem também a improvisadores musicais livres em um esforço para melhor compreender a formação idiomática que talvez tenham tido, bem como para refletir sobre sua prática atual de maneira um pouco mais ampla. Ademais, devido ao interesse deste artigo por processos de preparação para a improvisação livre, e o trabalho de Berkowitz tratar unicamente de improvisação idiomática, adotarei como referencia a expansão dos conceitos de Jeff Pressing oferecida pelos pesquisadores Rogério Costa e Stéphan Schaub. O fato de tratarmos, neste artigo, especificamente da improvisação livre não desfaz de forma alguma a importância do trabalho de Berkowitz em relação ao de Costa e Schaub. É através do primeiro autor que compreenderemos a maneira como importantes ideias das ciências cognitivas podem ser pensadas dentro da improvisação em diferentes formas e culturas. O foco de Costa e Schaub sobre a compreensão de dois conceitos de Jeff Pressing dentro da improvisação livre - referent e knowledge base - e a cuidadosa exposição de Berkowitz sobre diversos outros conceitos das ciências cognitivas, nos faz crer que as duas bibliografias são complementares em importância ainda que a segunda tome um número maior de linhas do presente artigo.

Aaron Berkowitz buscou em variadas fontes, informações que dessem pistas sobre a maneira como se dá a aquisição do domínio técnico e cognitivo da improvisação idiomática. As habilidades e práticas que descreve, no entanto, encontram-se muitas vezes no trabalho de um improvisador livre e quase sempre na formação musical que o antecede. $O$ resultado de seu cuidadoso estudo pode ser encontrado no livro, The Improvising Mind - Cognition and Creativity in the Musical Moment. O eixo principal desta pesquisa encontra-se no estudo de nove manuais de improvisação musical publicados na Europa entre os séculos XVIII e XIX. Em uma abordagem abrangente, o trabalho ofe- 
rece também uma exposição clara de princípios pedagógicos que atravessam não só os manuais europeus mas outras práticas improvisadas como Jazz, Hindustani, música iraniana, um certo tipo de poesia oral improvisada eslava e a aquisição de idiomas estrangeiros. Entre outras referências das ciências cognitivas, o trabalho recebe grande auxílio, como mencionei, das pesquisas de cognição e improvisação musical desenvolvidas pelo neurocientista e psicólogo cognitivista, Jeff Pressing.

Além deconceitos determinantes como referent eknowledge base, sobre os quais falarei mais adiante, Pressing descreve os processos cognitivos necessários à improvisação:

\begin{abstract}
O improvisador deve efetuar em tempo real, codificação perceptual, alocação ideal de atenção, interpretação de evento, tomada de decisão, previsão (das ações dos outros), armazenamento e resgate de memória, correção de erros, controle de movimentos, e além disso deve integrar estes processos em um conjunto maximamente ininterrupto de dizeres musicais que refletem tanto uma perspectiva pessoal sobre organização musical quanto uma capacidade de afetar quem escuta (PRESSING apud BERKOWITZ, 2010, p.4).
\end{abstract}

As habilidades acima, tomadas individualmente, oferecem largo terreno de pesquisa. Berkowitz faz uso de alguns termos das ciências cognitivas, que explicarei a seguir, para melhor compreendê-las. No primeiro capítulo de seu livro, o autor oferece uma breve contextualização dos estudos da cognição na improvisação. Nesta parte da obra, inclui discussões sobre aprendizado, memória e comparações entre linguagem verbal e música. Após este capítulo inicial, Berkowitz divide seu livro em duas partes. A primeira delas tem seu foco sobre a pedagogia e o aprendizado da improvisação, enquanto a segunda debruça-se sobre a cognição na performance improvisada. Nos concentraremos, neste artigo, na primeira parte.

Dois conceitos importantes apresentados nesta parte do livro são os de aprendizado implícito e aprendizado explícito. Berkowitz encontra, em pesquisas realizadas acerca do aprendizado de linguagens verbais, pistas para compreender as diferentes maneiras pelas quais nos apropriamos de determinadas habilidades e conteúdos.

O primeiro conceito do par que apresentei acima envolve a abstração inconsciente e automática da natureza estrutural de um material, na qual se chega pela experiência. Este processo pode ocorrer com pessoas que aprendem a falar livremente um idioma sem conhecer qualquer regra gramatical ou tocar fluentemente um instrumento musical sem conhecer os sistemas teóricos que seguem certas práticas. Berkowitz cita o linguista Nick Ellis que define o aprendizado implícito da seguinte maneira:

(...) a aquisição de conhecimento a respeito da estrutura subjacente de um ambiente de estímulos complexos por meio de um processo que ocorre naturalmente, de maneira simples e sem operação consciente (...)(PRESSING apud BERKOWITZ, 2010, p.7).

O aprendizado explícito, como o próprio nome parece sugerir, é uma operação mais consciente na qual o indivíduo além de buscar a informação, cria e testa hipóteses. Berkowitz aponta que embora sejam processos diferentes, estão frequentemente 
associados no aprendizado. O autor coloca que o sujeito frequentemente aprende coisas implicitamente enquanto se exercita explicitamente em algo. Quando lemos uma melodia, ou uma frase em uma língua qualquer, internalizamos elementos estruturais, formais e estilísticos que estão além do esforço consciente daquele momento. Os termos implícito e explícitos também são utilizados para a descrição de diferentes funcionamentos da memória que possui elementos que podem ser imediatamente atualizados (memória implícita) enquanto outros necessitam um esforço consciente (memória explícita).

Outra reflexão importante acerca da memória apresentada por Berkowitz é a distinção entre os conceitos de memória declarativa e memória procedimental. A primeira refere-se à habilidade de recordar fatos e eventos, avaliar ideias, "saber o que". A segunda, por sua vez, envolve o conhecimento de competências, memória muscular, geração de ideias, "saber como".

Dada a dificuldade em dominar todas as habilidades envolvidas na improvisação, Jeff Pressing descreve duas ferramentas abstratas importantes que ajudam a driblar as severas restrições das nossas capacidades de processamento de informação e ação. Estes conceitos, chamados de referent e knowledge base, podem ser de grande ajuda para compreender a aplicação de processos implícitos e explícitos e os usos dos diferentes tipos de memória. $O$ autor define referent da seguinte maneira:

\footnotetext{
um esquema formal subjacente ou guia para uma peça específica usada pelo improvisador para facilitar a geração e edição de comportamento improvisado...o referent oferece material para variação para que o performer precise alocar menos capacidade de processamento (atenção) para a seleção e criação de materiais (BERKOWITZ, 2010, p.4-5).
}

Costa e Schaub propõe em seu artigo Expanding the concepts of knowledge base and referent in the context of collective free improvisation, que o conceito de referent pode ser expandido para incluir qualquer estratégia local e específica, estabelecida pelos músicos durante ou antes da performance. Os autores citam como exemplos as partituras gráficas de Vinko Globokar e John Zorn. Podemos também lembrar do Treatise de Cornelius Cardew ou as instruções de Stockhausen em Intuitive Music. Costa e Schaub sugerem que palavras isoladas e imagens podem servir de referent, bem como olhares e sinais trocados entre os músicos, além do próprio devir (seu passado e presente) de uma improvisação livre pode se tornar um referente. O outro conceito que compõe o pensamento de Pressing refere-se ao conhecimento acumulado que o improvisador carrega para dentro do ambiente de criação.

O termo knowledge base, está relacionado à fluência improvisacional que depende de sua criação, manutenção, ampliação, e enraizamento na memória de longo prazo. Fazem parte de sua composição: 
materiais, fragmentos, repertório, habilidades, estratégias perceptivas, rotinas de resolução de problemas, estruturas e esquemas hierárquicos de memória, programas motores generalizados..." que são construídos na "memória de longo prazo dos performers" (PRESSING, 1998, p. 53).

Na música improvisada que se submete a um idioma específico, o knowledge base pode ser pensado como um sistema abstrato que inclui determinados materiais, acordes, escalas, sintaxes, etc. Contudo, conquanto possamos compreender knowledge base dentro de um contexto idiomático, como fez Berkowitz, Costa sugere que o termo também seja aplicável à improvisação livre se compreendido de maneira mais abrangente. A ideia de knowledge base passa a incluir, portanto, todo o passado sonoro e musical experimentado pelos improvisadores. Além disso, uma definição de knowledge base da improvisação livre deverá incluir também o "saber como", para lidar com o tempo, os outros, a escuta e as contingências. É sobre algumas das formas utilizadas para desenvolver fluência improvisacional e fortalecer o knowledge base encontradas nos materiais estudados, que Berkowitz procura refletir em sua obra.

O autor documenta e reflete a respeito de importantes estratégias pedagógicas nas diferentes manifestações citadas. Tanto nos métodos de improvisação de teclado publicados na Europa no século XVIII, quanto na língua falada, a repetição parece estar intimamente associada à criação de procedimentos e da gênese da internalização necessária à produção fluente. Além disso a variação e recombinação também parecem determinantes e podem ser vistas na abundância de material idiomático que deveria ser lido, estudado, decorado, variado e recombinado por quem se aventurasse a improvisar uma cadenza. A exaustão das possibilidades permitidas pelo idioma, indicam as fontes de Berkowitz, gera uma memória implícita capaz de improvisar tanto música quanto a fala. As comparações transculturais sugerem que fórmulas são aprendidas como estruturas flexíveis de maneira que a variação ou recombinação de um número limitado de padrões pode gerar uma proliferação de possibilidades.

Existem além dos aspectos observados por Berkowitz, habilidades subjetivas envolvidas na improvisação que não são abordadas diretamente em nenhum dos tratados citados e tampouco nas comparações transculturais. As únicas referências aparecem na descrição feita por Pressing, dos processos cognitivos necessários à improvisação que citei acima. Alocação ideal de atenção, interpretação de evento, tomada de decisão, previsão das ações dos outros, armazenamento e resgate de memória, são todas habilidades que, segundo a visão de Pressing, podem ser encontradas dentro destes processos improvisatórios observados por Berkowitz. Não são, no entanto, tema da pesquisa apresentada em seu livro que já cobre um amplo espectro. Felizmente, pistas a este respeito podem ser encontradas nos relatos colhidos pelo autor. Ao que sugere o material coletado, não era comum, como processo pedagógico musical, que se pensasse em como tomamos esta ou aquela decisão, ou como tornar-se mais apto a decidir bem, ou ainda, como ampliar nossas capacidades de interpretação de eventos e alocação de atenção. O que parece, porém, é que de forma tácita, estas habilidades faziam parte importante de diversos dos processos descritos por Berkowitz. Mozart, ao falar sobre improvisação em uma carta à sua irmã, diz: "Eu simplesmente faço a primeira coisa que 
vem na minha cabeça." (BERKOWITZ, 2010) Para Czerny, para além das estratégias de desenvolvimento técnico e fluência idiomática, deve-se "deixar tudo para os dedos e para a sorte" (BERKOWITZ, 2010).

\section{Conclusões}

Para o improvisador entrevistado por Aaron Berkowitz, Robert Levin, "improvisar é como andar na corda bamba". Neste cenário, olhar para o lado ou distrair-se pode ser trágico. A concentração, segundo este paralelo, apresenta-se como habilidade basal para a manutenção do fluxo improvisatório. A improvisação musical coletiva livre permite que diversas pessoas andem em cordas bambas diferentes que se cruzam, formando juntas um fluxo cuja manutenção depende de elementos de escuta, concentração, interação, confiança, decisão, energia, silêncio, memória, risco de quantas pessoas houver envolvidas. Improvisadores diferentes oferecem relatos variados de como pensam sobre estas habilidades e como acreditam que suas práticas se relacionam ao desenvolvimento delas. Processos diferentes revelam práticas que não raro envolvem quase toda a vida de quem improvisa. Improvisadores que, assim como os filósofos estudados por Foucault, descrevem um cuidado de si para improvisar que supõe um desenvolvimento total do sujeito.

Ao considerarmos as possibilidades de contribuição para a improvisação advindas destes processos de construção pessoal, deparamo-nos com uma série de virtudes que podem interessar a alguns improvisadores. Vislumbramos um sujeito tranquilo, concentrado, de escuta aberta, capaz de dizer o que se quer na hora exata e de reagir ao seu entorno de maneira eficiente em função de um todo. Vemos que voltar o olhar para si pode apresentar-se como um passo determinante na preparação para improvisar.

Para os gregos a busca da virtude ou da verdade, seja na música ou qualquer outro ofício, caminha junto com a construção do sujeito verdadeiro. Afora o desenvolvimento técnico e criativo, indispensável ao processo, o aprendiz lançará mão de ferramentas e estratégias que o permitirão exercitar continuamente este conhecimento de forma plena. Estas ferramentas supõe o desenvolvimento de seu caráter. Para tocar melhor, segundo esta lógica, além de possuir grande conhecimento teórico e prático a respeito do objeto que pretendo dominar, devo incansavelmente buscar ser o melhor ser humano que posso.

Sobre o conhecimento prático, há uma trajetória de aprendizado explícito e implícito que parece acompanhar as práticas musicais individuais. Entre os estudos mais específicos sobre o aprendizado da improvisação, as ciências cognitivas, como descritas pelos autores estudados neste artigo, oferecem ferramentas abstratas bastante úteis para a compreensão de desenvolvimentos diversos presentes na improvisação e sua preparação.

O processo improvisatório parece envolver um número incontável de fatores e afetos que interagem para gerar o resultado sonoro. As formas como nos ensinamos a agir, a não agir e a reagir às coisas que acontecem durante a improvisação, certamente 
interferem nos nossos processos de tomada de decisão. Junto com outras questões, como a maneira com que eventos externos e conjunturas psicológicas influenciam os rumos do som que se criará, podemos observar habilidades que auxiliam de maneira determinante a improvisação. Abrir mão dos próprios impulsos em função do que se ouve, saber dar e receber silêncio, tomar a frente quando parecer apropriado, são potências que podem ser desenvolvidas por improvisadores diferentes de formas muito variadas.

Cabe a esta reflexão um sentido um pouco mais amplo da preparação do que somente o treinamento dos músculos e tendões para que possam estar o mais próximo possível do fluxo de ideias musicais da criação em tempo real. A capacidade de responder a um presente tão volátil quanto o da improvisação musical coletiva livre parece algo que pode ser expandido e aprofundado de inúmeras formas. Pessoas envolvidas com esta busca frequentemente procuram auxílio em atividades que junto com a preparação técnica e teórica, tomam-lhe quase por inteiro os dias e a mente. A compreensão da preparação, amiúde, envolve bem mais do que as horas com o instrumento na sala de estudo. São adotadas atividades como yoga, meditação e corrida para aprontar os músculos, mas também a mente para longas sessões de trabalho. Estas práticas ensinam mais do que padrões de contração muscular adequados. São práticas que, como os filósofos que Foucault estudou, entendem o ser humano como um todo que deve ser desenvolvido. O projeto musical por vezes funde-se com um projeto de vida e de mundo. Na Áskesis os dias tornam-se parte de um processo de cultivo si para um fim: a aquisição da virtude. Penso na dedicação monástica de diversos músicos improvisadores que conheci. Vidas focadas de trabalho, regadas de abstinências e guiadas pela construção de um corpo de possibilidades criativo-sonoras. Histórias sofridas e outras mais brandas contam diferentes trilhas na construção de algo que capacita para a vida e para a improvisação.

\section{Referências bibliográficas}

ARTAUD, A. O Teatro e Seu Duplo. Brasil, Martins Editora, 2006

BERKOWITZ, A. The Improvising Mind - Cognition and Creativity in the Musical Moment. New York: Oxford University Press. 2010

COSTA, R. Estratégias pedagógicas para a prática da livre improvisação: diálogos entre a improvisação e a composição. In: XX Congresso da Anppom, 2010, Florianópolis. Anais do XX Congresso da Anppom. Florianópolis, 2010. p. 447-452.

Schaub, S. Expanding the concepts of knowledge base and referent in the context of collective free improvisation. XXIII Congresso da Anppom. Natal, 2013

FOUCAULT, M. A hermenêutica do sujeito. São Paulo: Martins Fontes, 2014.

GROTOWSKI, J.; BARBA, E.; FLASZEN, L. O Teatro laboratório de Jerzy Grotowski 1959-1969. São Paulo: Sesc/Perspectiva, 2010.

MINGUS, C. Saindo da Sarjeta. Rio de Janeiro. Jorge Zahar Editor, 2005

OLIVEROS, P. Deep listening A composer's sound practice. Lincoln: Deep Listening Publications, 2005 
SLOTERDIJK, P. Has de cambiar tu vida. Espanha. Pre-Textos, 2012

STANISLAVSKI, Constantin. A Preparação do ator. RJ: Civilização Brasileira, 1989.

TAMM, E. Robert Fripp From King Crimson to Guitar Craft. UK: Faber and Faber, 1990

PRESSING, Jeff. Psychological Constraints on Improvisational Expertise and Communication, in In the course of Performance: Studies in the World of Musical Improvisation. Ed. Bruno Nettl and Melinda Russel Chicago, (University of Chicago Press, 1998) 